\title{
Demographic and clinical factors predicting retention in methadone maintenance: results from an Irish cohort
}

\author{
C. D. Darker ${ }^{1}$ J. Ho ${ }^{1} \cdot$ G. Kelly $^{1} \cdot$ L. Whiston ${ }^{1} \cdot$ J. Barry $^{1}$
}

Received: 19 March 2014/Accepted: 16 May 2015/Published online: 31 May 2015

(C) Royal Academy of Medicine in Ireland 2015

\begin{abstract}
Background Retention in Methadone Maintenance Treatment (MMT) is superior to that of other therapies for opioid addiction, but with international retention rates around $50 \%$ after 1 year of treatment, there remains a need for improved retention rates.

Aims This study aimed to explore the demographic and clinical factors predicting retention in MMT.

Methods Face-to-face surveys with MMT patients in a Dublin methadone clinic were conducted. Retention was assessed by the presence and duration of breaks in treatment at any stage.

Results 189 patients participated in the study. $46 \%$ $(n=87)$ reported having at least one break in treatment, and the median duration of a break was 3 months. Age, current methadone dose and prescription of antipsychotic medication were significant predictors of retention. Patients who were older, single, living in their own home, on a higher dose of methadone, or taking antipsychotic medications had fewer breaks in treatment. Males tended to have significantly longer breaks. Patients reported that the main reasons for breaks were relapse into drug use $(21.8 \%, n=19)$, incarceration $(11.4 \%, n=10)$, weary of MMT $(13.7 \%, n=12)$ or problems at the clinic $(10.3 \%, n=9)$. Factors enabling regular attendance included wanting to get or stay clean $(37.5 \%, n=51)$, avoidance of withdrawal symptoms $(16.1 \%, n=22)$,
\end{abstract}

C. D. Darker

Catherine.darker@tcd.ie

1 Department of Public Health and Primary Care, Trinity Centre for Health Sciences, Trinity College Dublin, Tallaght Hospital, Dublin 24, Ireland methadone dependence $(13.9 \%, n=19)$ and services provided $(10.2 \%, n=14)$.

Conclusion Patients who were older, single, living in their own home, on a higher dose of methadone, or taking antipsychotic medications had fewer breaks in treatment.

Keywords Methadone maintenance therapy - Retention · Demographic factors $\cdot$ Clinical factors

\section{Introduction}

Ireland has the highest rate of heroin use in the EU, estimated at $8 / 1000$ people [1]. There are several approaches to the treatment and harm reduction of heroin addiction, including managed withdrawal, methadone maintenance therapy (MMT) and psychosocial interventions. Provision of methadone is the main substitution intervention for opiate users in Ireland [2]. In 2011, there were 10,711 patients receiving methadone treatment [3]. MMT in Ireland is provided in a tiered approach to the problems ranging from large specialist clinics with multidisciplinary teams where more chaotic patients attend to primary care settings with GPs or pharmacies where more stable patients attend [4]. The most recent nationally available data examining trends in treated problem drug use in Ireland between 2005 and 2010 [5] indicate that the majority of cases $(68 \%)$ received treatment in specialised outpatient settings, with approximately $22 \%$ of cases treated by GPs in the community. The number of cases entering treatment in GP settings decreased by $15 \%$ over the reporting period, which reflects the cohort of stable patients attending GPs. Retention of patients in both outpatient and GP services, reflected in cases continuing in methadone treatment from previous years, is stable with little change over time. 
Methadone is a slow-onset, long-acting opioid agonist used in the treatment of heroin addiction [6]. It reduces heroin use by increasing the tolerance to opioid effects, as well as reducing withdrawal symptoms [6]. It is taken orally and is well absorbed, binding to blood proteins [7]. Side effects of methadone include drowsiness, constipation, respiratory problems, depression and cardiac arrhythmia [8-10]. Of the various treatments available, MMT in combination with medical and psychosocial services is believed to be most effective [11].

MMT has important beneficial effects including the reduction of drug use, HIV related and risky behaviours [2, 11-15]. The Research Outcomes Study in Ireland (ROSIE), a prospective longitudinal multi site drug treatment study, included a cohort of over two hundred methadone patients. This study reported a decrease in polydrug use, the number of days of drug use and level of consumption for heroin, unprescribed methadone, unprescribed benzodiazepines and cocaine between treatment intake and 1 year followup. A statistically significant reduction in intravenous use for cocaine, heroin and benzodiazepines was also illustrated [2]. Long tenure in MMT has been associated with health and psychosocial benefits such as improved social functioning, increased employment and a reduction in criminal involvement $[2,7,15,16]$.

Retention in MMT is important because of its associated benefits for patients and the possible negative consequences of premature exit. Unplanned exit from treatment can lead to relapse to drug use, injecting and other high risk behaviours [17]. There is also a greater risk of drug-mediated mortality in the 30 days after dropout or discharge from MMT [18]. However, a significant proportion of opiate-dependent patients fail to remain in methadone treatment over a sustained period of time. One-year retention rates vary between different countries: 40-45\% in Canada [19], $62 \%$ in the UK [20], $40 \%$ in Italy [20], $69 \%$ in Switzerland [21], and 25-60\% in the US [20]. In Ireland, one-year retention rate is relatively high at $79 \%$ [2]. In Ireland, there has been a very proactive strategy to maintain retention in treatment, through dosing policy and regular communication with prescribing doctors. A single database records retention data and has done since the methadone programme was instituted in 1993 [4].

Previous studies have identified several variables that predict retention in MMT. Some of the main patient characteristics that predict retention are female gender [20, 22-24], older age (>30 years) [20, 21, 23, 24, 25], stable living conditions [21], good health [13], high level of education [24, 25], being married, increased psychological stability, intact social support networks, employment [20, $24]$ and minimal criminal history $[13,20]$. A number of factors associated with drugs have been linked with retention such as prior treatment experience [21], shorter and milder drug abuse history, older age of first drug use, less frequency of drug use, not injecting drugs and minimal contact with other drug users [20, 24, 25]. Programme factors include a higher methadone dose generally above $60 \mathrm{mg}$ a day [13, 22, 24-29], greater treatment satisfaction [13, 27], primary care treatment setting [22, 23] and counselling support [13].

Patients who prematurely discharged from MMT within the first 6 months of treatment in Baltimore were interviewed to establish reasons for exiting treatment. The primary reasons for exiting treatment included incarceration and programme- related factors such as disagreeing with programme rules, conflict with staff and schedule conflicts [30]. Previous research in an Irish MMT setting has acknowledged the need for more research on the type of factors which contribute most to retention, treatment satisfaction and the reasons why patients take breaks from treatment [2, 22]. This study will aim to address these gaps in knowledge working to identify demographic and clinical factors associated with retention in treatment in a cohort of opiate-dependent methadone-maintained patients receiving treatment in Ireland.

\section{Methodology}

This cross-sectional study was conducted in the largest urban methadone maintenance treatment clinic in Ireland in March 2012. This clinic provides interdisciplinary psychiatric, psychological, social and medical services. Patients completed a researcher-administered questionnaire.

The questions comprised three categories: demographic factors, clinical factors and open-ended questions (see Appendix A: Questionnaire). Demographic factors included age, gender, ethnicity, level of education, type of housing, number of cohabitants, current neighbourhood, marital status, number of children, employment and car ownership. Clinical factors were age started taking heroin, route of administration, neighbourhood at that time, length of time in methadone treatment, duration of current MMT episode, starting and current methadone dose, interruptions in methadone treatment, other medications and frequency of GP visits. Open-ended questions included reasons for the patient's last break in treatment (if any), and factors helping the patient to attend the clinic regularly.

This study received ethical approval from Faculty of Health Sciences Ethics Committee, Trinity College, Dublin. Patients were provided with information sheets on the study, and informed consent was obtained from all patients.

SPSS 21 statistics software was used for the analysis of the data. Retention in treatment was assessed by the presence or absence of breaks in treatment, and the duration of 
longest break, if applicable. A binary logistic regression was carried out for all demographic factors to identify significant factors predicting breaks in treatment. Then, each variable was individually cross-tabulated with breaks in treatment. Significance was assessed by Pearson Chisquared test. For variables with small sample sizes (e.g. antipsychotic medications), significance was assessed by Fisher's exact test. A non-parametric test (Independent samples Kruskal-Wallis test) was used to assess significance for highly skewed data. The open-ended questions were examined for common themes.

\section{Results}

\section{Response rate}

A total of 189 patients out of 300 patients in the clinic $(63 \%)$ answered the questionnaire.

\section{Profile of respondents}

A profile of the 189 respondents is presented in Table 1 . The variables are presented according to whether respondents had a break from MMT or not. In both groups of respondents, both with and without breaks in treatment, the majority of respondents were male, Irish, single, and unemployed with an education level of junior certificate or below. The median age for starting opioid use was 18 for those with a break from treatment and 17 for those without a break from treatment. Those with a break from treatment have been engaged with MMT for slightly longer than those without a break (96 and 84 months, respectively); however, the reverse is present when the duration of current treatment episode is examined (24 and 36 months, respectively). In relation to current dose of methadone, $47.7 \%$ of those who reported having a break from MMT were being dispensed a dose of methadone above $60 \mathrm{mg}$ per day, while $67.7 \%$ of those who did not have a break from treatment received a dose of methadone higher than $60 \mathrm{mg}$ per day.

Demographic information relating to non-responders was not formally noted in this study. However, the most recent nationally available demographic information relating to cases of treated problem drug use in Ireland by the National Drug Treatment Reporting System [5] indicates that in 2010 the median age nationally is 28 years, and the percentage of male patients receiving methadone is $72.5 \%$. Our cohort is therefore slightly older but with relatively the same proportion of males accessing treatment in the service in which this research took place.

\section{Breaks in treatment}

Never having a break in treatment was reported by $54 \%$ $(n=102)$. Of the remaining $46 \%(n=87)$ respondents who did report breaks in treatment, the majority $(83.9 \%$, $n=73$ ) reported only one break. The highest number of breaks in MMT reported was $5(n=1)$. The duration of the longest breaks in MMT varied from less than 1 month to longer than 12 months as illustrated in Table 2. The median duration of breaks in treatment was 2 months $(\mathrm{SD}=1.1)$.

\section{Demographic factors which predict retention in MMT}

A binary logistic regression was conducted to examine the likelihood of respondents having breaks from MMT based on demographic factors. The final model including 3 independent variables, age, marital status and type of housing, was statistically significant and fits the data well $\left[\chi^{2}\right.$ (3) $=9.168, \quad p=0.027$; Hosmer and Lemeshow, $p>0.05]$. Analysis of the data using a binary logistic regression revealed that age was a statistically significant predictor of breaks in treatment (Table 2). No other demographic factors including gender, level of education and employment status impacted on breaks in treatment.

Age was significantly associated with breaks in MMT [OR (95 \% CI): 0.939 (0.891-0.989), $p=0.018$ ]. Those who are older are less likely to have experienced breaks in treatment. Being homeless seems to be linked with having had a break in MMT, and living in one's own home aligned with not having any breaks in treatment. However, this association is not significant [OR $(95 \% \mathrm{CI}): 0.813$ (0.641-1.030), $p=0.087$ ]. Being single appears to be connected with not having any break in treatment, and cohabitating was associated with having had a break in MMT. Again, this relationship is not significant [OR (95\% CI): 1.195 (0.909-1.571), $p=0.201]$.

\section{Clinical factors predicting breaks in treatment}

The relationship of all clinical factors, including age at first opioid use, starting and current methadone dose, length of time in MMT, duration of current MMT episode, medication prescribed and whether GP was attended in the clinic or in community, with prevalence of breaks in treatment was examined through binary logistic regression. The final model with the best fit was statistically significant $\left[\chi^{2}\right.$ $(5)=15.784, \quad p=0.007$; Hosmer and Lemeshow, $p>0.05]$ and included current dose of methadone, length of time in methadone and duration of current treatment episode. All factors were significantly associated with incidence of breaks in treatment. Those who reported a 
Table 1 Demographic and clinical profile of patients by the presence of a break in MMT

\begin{tabular}{|c|c|c|}
\hline Factors & $\begin{array}{l}\text { Participants with a break from } \\
\text { MMT } N=87(46 \%)\end{array}$ & $\begin{array}{l}\text { Participants with no break } \\
\text { in MMT } N=102(54 \%)\end{array}$ \\
\hline Gender & $\left(\chi^{2}(1)=0.005, p=0.943\right)$ & \\
\hline Female & $29.9 \%$ & $29.4 \%$ \\
\hline Male & $70.1 \%$ & $70.6 \%$ \\
\hline \multirow[t]{2}{*}{ Age (median) } & $\left(\chi^{2}(3)=5.821, p=0.121\right)$ & \\
\hline & $33(\mathrm{SD}=7.2)$ & $36(\mathrm{SD}=6.7)$ \\
\hline \multicolumn{3}{|l|}{ Ethnicity } \\
\hline Irish & $97.7 \%$ & $97.1 \%$ \\
\hline Non-Irish & $1.1 \%$ & $2.0 \%$ \\
\hline Marital status & $\left(\chi^{2}(2)=8.764, p=0.12\right)$ & $78.4 \%$ \\
\hline Single & $58.3 \%$ & $17.6 \%$ \\
\hline Cohabiting & $34.5 \%$ & $3.9 \%$ \\
\hline Married & $7.1 \%$ & \\
\hline Education & $\left(\chi^{2}(4)=3.399, p=0.493\right)$ & \\
\hline Primary incomplete & $7.1 \%$ & $5.0 \%$ \\
\hline Primary complete & $32.9 \%$ & $30.0 \%$ \\
\hline Junior certificate & $32.9 \%$ & $45.0 \%$ \\
\hline Leaving certificate & $14.1 \%$ & $12.0 \%$ \\
\hline Third level & $12.9 \%$ & $8.0 \%$ \\
\hline Housing & $\left(\chi^{2}(4)=7.349, p=0.119\right)$ & \\
\hline Homeless & $7.6 \%$ & $1.1 \%$ \\
\hline Hostel & $30.4 \%$ & $27.7 \%$ \\
\hline Others home & $15.2 \%$ & $18.1 \%$ \\
\hline Rented & $20.3 \%$ & $14.9 \%$ \\
\hline Own & $26.6 \%$ & $38.3 \%$ \\
\hline Employment & $\left(\chi^{2}(1)=0.067, p=0.796\right)$ & \\
\hline Employed & $5.7 \%$ & $4.9 \%$ \\
\hline Unemployed & $94.3 \%$ & $95.1 \%$ \\
\hline Age first opioid use & 18 & 17 \\
\hline \multirow[t]{2}{*}{ Length in MMT } & $\left(\chi^{2}(3)=1.408, p=0.704\right)$ & \\
\hline & 110 months & 100 months \\
\hline Starting methadone dose & $\left(\chi^{2}(5)=4.359, p=0.499\right)$ & $22.2 \%$ \\
\hline $0-20$ & $24.4 \%$ & $28.9 \%$ \\
\hline $21-40$ & $35.4 \%$ & $16.7 \%$ \\
\hline $41-60$ & $17.1 \%$ & $18.9 \%$ \\
\hline $61-80$ & $13.4 \%$ & $13.3 \%$ \\
\hline$>80$ & $9.7 \%$ & \\
\hline Current methadone dose & $\left(\chi^{2}(5)=15.372, p=0.009\right)$ & \\
\hline $0-20$ & $8.1 \%$ & $5.9 \%$ \\
\hline $21-40$ & $16.3 \%$ & $11.8 \%$ \\
\hline $41-60$ & $27.9 \%$ & $14.7 \%$ \\
\hline $61-80$ & $32.6 \%$ & $35.3 \%$ \\
\hline$>80$ & $15.1 \%$ & $32.4 \%$ \\
\hline GP in the community & $48.8 \%$ & $39.0 \%$ \\
\hline Number of GP visits per year (mean) & 2.49 & 4.60 \\
\hline
\end{tabular}

longer duration of current MMT episode [OR (95\% CI): $0.775(0.639-0.940), p=0.009$ ] or less than one year MMT overall [OR (95 \% $\mathrm{CI})$ : 0.199 (0.052-0.755), $p=0.018$ ] were significantly less likely to have experienced breaks in treatment. Patients who reported a higher current dose of methadone were significantly less likely to have experienced breaks in MMT [OR (95\% CI): 2.197 (1.118-4.317), $p=0.022]$. The higher the current 
Table 2 Binary logistic regression of demographic factors which predict breaks in MMT

\begin{tabular}{llll}
\hline $\begin{array}{l}\text { Explanatory } \\
\text { variable }\end{array}$ & \multicolumn{3}{l}{ Breaks in treatment } \\
\cline { 2 - 4 } & $\begin{array}{l}\text { Odds } \\
\text { ratio }\end{array}$ & $\begin{array}{l}\text { 95\% Confidence } \\
\text { interval }\end{array}$ & $P$ value \\
\hline Age & 0.93 & $(0.89,0.98)$ & 0.018 \\
Marital status & 1.19 & $(0.90,1.57)$ & 0.201 \\
Type of housing & 0.81 & $(0.64,1.03)$ & 0.087 \\
\hline
\end{tabular}

methadone dose the less likely the participant was to report having a break in MMT. Notably, a change occurred at methadone doses of $61 \mathrm{mg}$. At $61 \mathrm{mg}$ of methadone, there was a switch from the majority of patients having breaks to the majority of patients not having breaks. All patients in our sample receiving $>101 \mathrm{mg}$ of methadone reported no breaks in treatment as depicted in Fig. 1 below.

Due to the small number of patients on antipsychotic drugs $(n=10)$, logistic regression was not possible. A cross tabulation Chi-square test examining the relationship between prescription of antipsychotic medication and incidence of breaks in treatment revealed a significant relationship $\left[\chi^{2}(1)=5.518, p=0.19\right]$. Of those who were dispensed antipsychotic medicine, 9 reported no breaks in MMT with only 1 respondent reporting a break in treatment. From this it is clear that patients taking antipsychotic medication appeared to have fewer breaks.

\section{Number and duration of breaks from MMT}

The number of reported breaks in treatment was within the range of 1-5 breaks in MMT. The majority of the sample who reported breaks in treatment experienced only 1 break in treatment $(83.9 \%, n=73)$. No demographic or clinical factors were significantly associated with the number of breaks in treatment.

The duration of the longest breaks in MMT varied from less than 1 month up to 18 months as illustrated Table 2. In the entire dataset, the distribution of the longest break was highly skewed towards the left. The median duration was 3 months $(\mathrm{SD}=33.8)$. Because of the highly skewed

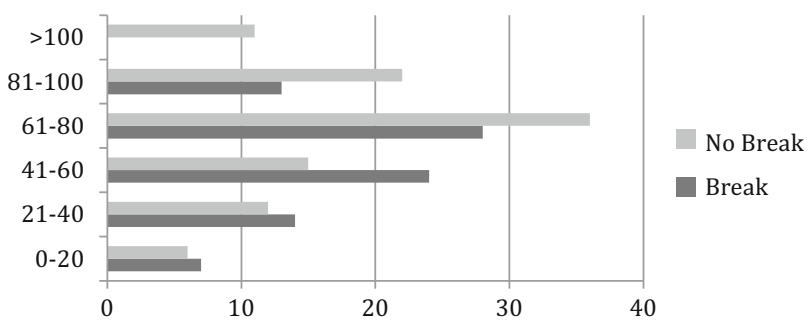

Fig. 1 Current methadone dose and prevalence of breaks in treatment

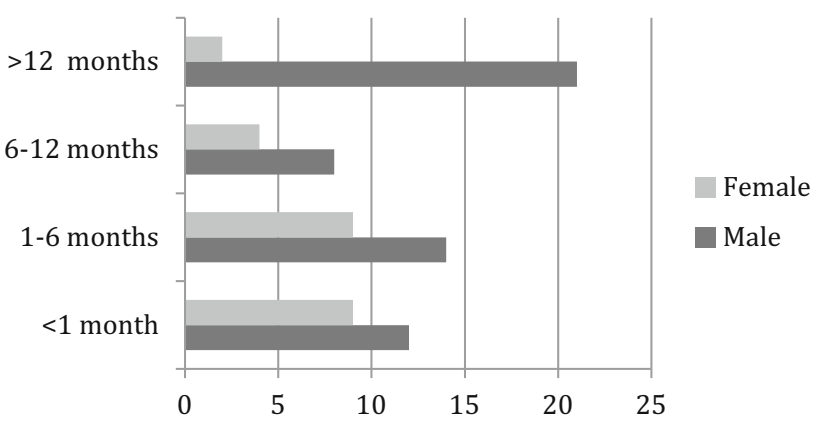

Fig. 2 Duration of breaks in treatment by gender

distribution, non-parametric tests were employed to identify significant predictors of duration of breaks in treatment. The duration of longest break from methadone treatment appeared to differ between males and females. An independent Kruskal-Wallis test showed this relationship to be significant $\left(\chi^{2}(1)=7.83, p<0.005\right)$. As illustrated in Fig. 2, males tend to have longer breaks from treatment than females. No other demographic or clinical factors were significantly associated with duration of longest break from MMT.

\section{Reasons for attending and dropping out of treatment}

A variety of reasons were put forward for breaks in treatment by those respondents who reported having a break in treatment. The most common reasons for breaks in treatment included relapse to drug use $(n=19,21.8 \%)$, being fed up of methadone, wanting to detox or enter another modality of treatment $(n=12,13.7 \%)$, being in prison or court and having problems with the police $(n=10$, $11.4 \%)$ and problems with the clinic such as fighting outside, difficulty making clinic times or travelling to the clinic $(n=9,10.3 \%)$. Other reasons reported by the remaining respondents included being clean $(n=7,8.0 \%)$, not wanting to take methadone while pregnant $(n=3$, $3.4 \%)$, being abroad $(n=6,6.8 \%)$, emotional events such as family bereavements, splitting up with partner $(n=4,4.5 \%)$, sickness $(n=3,3.4 \%)$ and lazy, no reason, lack of support, needing a break $(n=1,1.14 \%)$.

A number of factors were identified by respondents in enabling regular MMT attendance. The main factors encouraging treatment attendance were wanting to get or to stay clean $(n=51,37.5)$, to avoid sickness $(n=22$, $16.1 \%)$, methadone dependence $(n=19,13.9 \%)$ and the level of services provided in the clinic by staff $(n=14$, $10.2 \%)$. Other influential factors were withdrawal symptoms $(n=7,5.1 \%)$, family members $(n=7,5.1 \%)$, and only having to come in a few times a week $(n=6,4.4 \%)$. 


\section{Discussion}

The aim of this study was to identify the demographic and clinical factors that influenced retention in methadone treatment. Retention was measured by the presence of breaks in treatment and the duration of breaks longer than 28 days. Patients who were older, single, living in their own home, on higher doses of methadone, or on antipsychotic medication were less likely to have experienced breaks in treatment. Factors enabling MMT attendance and reasons for breaks in treatment were also explored adding to the currently available literature.

\section{Demographic factors}

The effect of age was in agreement with previous studies. A retrospective cohort study of over forty thousand individuals prescribed opioid replacement therapy between 1985 and 2006 in Australia found that age had the biggest impact on risk of leaving treatment with older respondents having a lower prevalence of breaks in treatment [23]. This finding was replicated in similar large cohort studies in Switzerland, Shanghai, America and Ireland [21, 22, 25, 31]. These studies focused primarily on breaks in treatment in last 12 months, while our research asked patients whether they ever had a break in treatment at any time. Older patients would have once been in the younger age category, so it would be expected that they would have a similar if not greater rate of breaks in treatment. However, it was found that older patients had fewer breaks than younger patients. This effect may be due to changes in social factors and health policy. The age started methadone treatment may be a more precise predictive factor of methadone retention.

The current study revealed that single people have longer retention rates while those who are cohabiting have shorter retention rates. However, neither finding was statistically significant. This result is in opposition with previous studies which have reported that having a spouse or partner predicts longer retention [24, 26, 32]. Interview experience suggests that this conflicting result may be due to the tendency for some patients to identify themselves as single even though they were in fact living with a partner. This was done by several patients, who subsequently switched to cohabiting upon further questioning by the investigator.

Bad living conditions have been presented as a predictor of lower treatment retention from a secondary analysis of registry-based data of 2880 MMT patients in Switzerland [21]. A randomised trial of 245 attendees at publically funded MMT in Baltimore corroborates this finding [33]. This is also verified by the current study which revealed that those who are homeless or in unstable housing are more likely to have experienced breaks in MMT.
The only factor that was found to predict longer breaks from treatment was gender. Males tended to have longer breaks than females. Gender predicted retention in some previous studies [31] but not in others [13]. Findings generally favour females having a higher retention rate [22]. For example, a literature review of 19 studies on retention in MMT and predicting factors in China between 2004 and 2012 reported females having a higher retention rate than males [24].

\section{Clinical factors}

The positive relationship found in the current study between methadone dose and breaks in treatment strengthens the existing literature. It is evident from the literature that higher methadone doses are a well-known predictor of retention $[26,28,29]$. A national cohort study of MMT patients in Ireland recounted that patients who receive less than $60 \mathrm{mg}$ were three times more likely to leave treatment before 12 months. Strongest increases in retention were reported between dosages from 20 to $60 \mathrm{mg}$ with modest gains after that up to a ceiling of $100 \mathrm{mg}$ [22]. This is similar to the findings of the current study in which there was a change at $61 \mathrm{mg}$ from the majority of patients having breaks to the majority of patients not having breaks.

The effect of antipsychotic drugs on breaks in treatment was unexpected. Patients on antipsychotics tended to have fewer breaks. It should be noted that the number of patients on antipsychotic medications was relatively small. However, the result was still statistically significant according to the Fisher's exact test, which is used for small samples. There are relatively few reports about schizophrenic patients and methadone treatment with even less focusing on retention. From what research is available, it has been reported that the atypical antipsychotic, Olanzapine, may increase retention in schizophrenia patients with opiate addiction [13, 34]. Methadone has very occasionally been used to treat psychotic symptoms [35], which may be part of an explanation of this putative effect.

\section{Reasons for breaks and staying in MMT}

In the current study, relapse into drug use was one of the main reported reasons for a break in treatment. Another Irish-based study reported that $39 \%$ of patients exiting treatment before the end of 12 months because of treatment failure which included returning to opiate use [22]. A review and meta analysis of forty-three studies $(20,873$ studies participants) reported reasons for drop out from MMT in China found that among the drop-outs, about one-fourth of the participants $(22.2 \%)$ were arrested by police and sent to detention centres due to relapse in drug use (positive urine test) during the course of MMT, $19.1 \%$ self-withdrew and $13.3 \%$ were due to relocation to another city outside the 
clinic coverage. Other drop out reasons such as criminal activities $(7.6 \%)$, unregistered by the MMT clinics $(6.3 \%)$, death and sickness $(6.3 \%)$ and dosage issues $(0.1 \%)$ were also reported. [12]. According to a systematic literature review of Pubmed articles, seven studies reported that methadone reduced heroin cravings, while four suggested that patients in MMT were still susceptible to heroin cravings [36]. It is possible that for some patients, methadone does not reduce heroin cravings, leading to relapse into heroin addiction. Other reasons for breaks in treatment included incarceration or criminal activity, problems with the clinic including inability to travel to the clinic, illness and transferring to another treatment modality. These are similar to reasons for treatment exit espoused in other studies [22]. A review and meta-analysis of research in China revealed that of those who exited treatment 13.3 . \% did so as they were relocated outside of treatment areas, $7.6 \%$ because of criminal activities and $6.3 \%$ due to illness [12].

Limited data on factors enabling treatment attendance were strengthened with an examination of what encourages MMT retention. One of the factors which contributed to patients attending clinics was to avoid withdrawal symptoms. Heroin withdrawal symptoms include vomiting, abdominal cramps, anxiety, bones and muscles aches, restlessness, perspiration, tremor, runny nose and tearing, goosebumps, pupil dilation, hot and cold flushes [37]. Symptoms usually peak after 24-72 h after last dose [38], but some symptoms such as depression and insomnia may persist for weeks or months. Other factors which also encouraged attendance included the services provided at the clinic by the staff such as doctors, social workers and counsellors. This corroborates research with veterans attending 8 MMT clinics between 2000 and 2002 based on a behavioural model which presented greater treatment satisfaction as one of the strongest predictors of 1 year retention [27]. The Drug Abuse Treatment Outcome Study (DATOS) in America looked at treatment outcomes for 1, 540 patients who entered MMT in 1991-1993. This research reported that 360 days retention in MMT is significantly associated with treatment satisfaction with increases in retention by $58 \%$ [14].

\section{Strengths and limitations}

A strength of this study is the collection of data on reasons for breaks from treatment as well as reasons for staying in treatment on which there is only limited literature available. An additional strength of this research is the respectable response rate of $63 \%$ through face-to-face researcher administered questionnaire, coupled with low level of missing data. In interpreting these findings, it should be noted that this study has limitations. A methodological limitation of this study was the moderate sample size. Of 300 available patients, 189 recruited for the study providing a moderate sample size in relation to the large number of predictor variables examined. However, appropriate statistical methods were employed and yielded similar answer results as previous studies which would suggest that insufficient power due to sample size was not an issue. The research questions aimed to look at retention in MMT of those patients already attending for treatment. No attempt was made to correct for patients registered to the treatment list and currently not attending. As a result, the sample may be biased to reflect less severe cases.

A number of recommendations arise from this study. The first is that prescribing patients a higher methadone dose may improve retention in methadone treatment. A significant link has been identified between methadone dose and retention in this and numerous other studies. However, it is important to note that any increase in methadone dose needs to be balanced with side effects-respiratory depression, constipation, hypotension, drowsiness and increased dependencethat may occur at higher concentrations [39]. The second treatment implication is that prescription of antipsychotic medication to patients with psychotic disorders may improve retention in that population [34]. Finally, a number of areas that would benefit from further research can be identified. While most studies measured retention in terms of length of time enrolled in treatment [13, 31], this study focussed on breaks in treatment. One line of further investigation may be the association between breaks in treatment and patient outcomes. The impact of schizophrenia on heroin addiction and methadone treatment is another relatively unexplored area. Finally, the demographic groups exhibiting significant differences in breaks from treatment could be studied further to understand the underlying causes for such effects and aid MMT administrators and staff in improving patient retention.

This study found that age, gender, marital status, type of housing, methadone dose and antipsychotic medications influenced retention in methadone treatment. Patients who were older, single, living in their own home, on higher doses of methadone, or on antipsychotic medication had a lower rate of breaks in treatment. These findings lead to several implications. A higher methadone dose and antipsychotic medications for patients with schizophrenia may improve retention in methadone treatment. Further research on the association between treatment breaks and outcomes, antipsychotic medication and retention and the underlying causes of demographic factors linked with retention could aid patient retention. This study adds to current literature addressing the gap on factors enabling MMT attendance and reasons for breaks from treatment.

Acknowledgments We thank the patients involved in this research.

Conflict of interest None to declare.

Ethical standard The current study has been approved by the Drug Treatment Centre Board Ethics Committee and has therefore been performed in accordance with the ethical standards laid down in the 1964 Declaration of the Helsinki and its later amendments. 


\section{Appendix A: Questionnaire}

Date:

1. Age:

2. Gender:

3. Ethnicity:

4. Level of education:
Time:

Male

White Irish

Incomplete Primary Leaving Cert
Researcher:
Participant Identity Code:

5 (a).

\begin{tabular}{l|l} 
& Nights(0-30) \\
\hline Relatives/partners/friends/others home: circle & \\
Own or rented home & \\
Hostel or other temporary accommodation & \\
On the streets (homeless) & \\
Prison/other detention/police station & \\
Hospital/residential treatment & \\
Other (please specify) &
\end{tabular}

5 (b). Number of people living in accommodation :

6. Current neighbourhood or postcode:

7. Marital status: Married Sing

8. Number of children:

Single

Divorced

Widowed

Cohabiting

9. Employment: Full time

If employed please specify:

10. Car ownership: Yes

Part time

Unemployed

11 (a). Age started taking opiates:

11 (b). Smoking or Injecting (Please circle)

12. Neighbourhood at that time:

13. Length of time in methadone treatment: ___ (number of months)

14. Length of time of current methadone treatment: (number of months)

15. Starting methadone dose: $0-20 \mathrm{mg} \quad 21-40 \mathrm{mg}$ $101-120 \mathrm{mg}$

16. Current methadone dose: $0-20 \mathrm{mg}$ $>121 \mathrm{mg}$ 41-60mg $21-40 \mathrm{mg}$

17. Any interruptions (breaks) in methadone treatment: Yes

17. Any interruptions (breaks) in methadone treatment: Yes

$41-60 \mathrm{mg}$ $61-80 \mathrm{mg}$ $81-100 \mathrm{mg}$ If yes, specify when and for how long?

18. Other medications/prescriptions: Yes If yes, please specify:

19. Frequency of GP(Community gp) visits per year:

20. Think about your last break in treatment- what where the reasons for this?

21. Think about the times when you were attending regularly- what helped you to continue to attend?

\section{References}

1. Addiction. EUEMCfDaD (2011) Annual report 2011: the state of the drug problems in Europe. EMCDDA, Luxembourg

2. Cox G, Comiskey C, Kelly P (2007) ROSIE findings 4: summary of 1-year outcomes: methadone modality. National Advisory Committee on Drugs, Dublin

3. Board DTC (2012) Annual report 2011. Drug Treatment Centre Board, Dublin

4. Farrell M, Barry J (2009) The introduction of the national opioid treatment protocol. HSE, Dublin
5. Bellerose D, Carew AM, Lyons S (2011) Trends in treated problem drug use in Ireland 2005-2010. Health Research Board, Dublin

6. Gonzalez G, Oliverto A, Kosten TR (2002) Treatment of heroin (diamorphine) addiction: current approaches and future prospects. Drugs 62(9): 12

7. Ward J, Bell J, Mattick R et al. (1996) Methadone maintenance therapy for opioid dependence: a guide to appropriate use. CNS Drugs 6(6):9

8. Chekuria V, Gerberb D, Brodiec A, Krishnadasd R (2012) Premature ejaculation and other sexual dysfunctions in opiate de- 
pendent men receiving methadone substitution treatment. Addict Behav 37(1):2

9. Fredheim OMMK, Borchgrevink PC, Kaasa S, Dale O (2008) Clinical pharmacology of methadone for pain. Acta Anaesthesiol Scand 52:10

10. Schmittner J, Schroeder J, Epstein D, Preston K (2005) Menstrual cycle length during methadone maintenance. Addiction 100:7

11. Addiction. NCPoEMToO (1998) Effective medical treatment of opiate addiction. JAMA 280(22):7

12. Zhang L, Chow EPF, Zhuang X, Liang Y, Wang Y, Tang C, Ling L, Tucker JD, Wilson DP (2013) Methadone maintenance treatment participant retention and behavioural effectiveness in China: a systematic review and meta-analysis. PloS one 8(7):e68906 (1932-6203 (Electronic))

13. Kelly SM, O'Grady KE, Mitchell SG, Brown BS, Schwartz RP (2011) Predictors of methadone treatment retention from a multisite study: a survival analysis. Drug Alcohol Depend 117(2-3):170-175

14. Simpson DD, Joe GW, Brown BS (1997) Treatment retention and follow-up outcomes in the Drug Abuse Treatment Outcome Study (DATOS). Psychol Addict Behav 11(4):294-307

15. Gossop M, Marsden J, Stewart D (2001) NTORS after five years the national treatment outcome research study: changes in substance use, health and criminal behaviour during the five years after intake. Crown Copyright, London

16. Oliver P, Keen J, Rowse G, Ewins E, Griffiths L, Mathers N (2010) The effect of time spent in treatment and dropout status on rates of convictions, cautions and imprisonment over 5 years in a primary care-led methadone maintenance service. Addiction 105(4):732-739

17. Cox J, Allard R, Maurais E, Haley N, Small C (2013) Predictors of methadone program non-retention for opioid analgesic dependent patients. J Subst Abuse Treat 44(1):52-60

18. Cosusins G, Teljeur C, Motterlini N, McCowan C, Dimitrov BD, Fahey T (2011) Risk of drug-related mortality during periods of transition in methadone maintenance treatment: a cohort study. J Subst Abus Treat 41(3):8

19. Nosyk B, Marsh D, Sun H, Schechter M, Anis A (2010) Trends in methadone maintenance treatment participation, retention, and compliance to dosing guidelines in British Columbia, Canada: 1996-2006. J Subst Abuse Treat 39(1):9

20. National Institute of Drug Abuse (2007) National institute on drug abuse international programme. National Institute on Drug Abuse, Bethesda

21. Huissoud T, Rousson V, Dubuois-Arber F (2012) Methadone treatments in a Swiss Region, 2001-2008: a registry-based analysis. BMC Psychiatry 12:238

22. Mullen L, Barry L, Long J, Keenan E, Mulholland D, Grogan L, Delargy I (2012) A national study of the retention of Irish opiate users in methadone subsitution treatment. Am J Drug Alcohol Abus 38:6

23. Burns L, Randall D, Hall WD, Law M, Butler T, Bell J, Degenhardt L (2009) Opioid agonist pharmacotherapy in New South Wales from 1985 to 2006: patient characteristics and patterns and predictors of treatment retention. Addiction 104(8):1363-13672
24. Zhou K, Zhuang G, Zhuang G. Retention in methadone maintenance treatment in mainland China, 2004-2012: a literature review. doi:10.1016/j.addbeh.2013.09.001 (1873-6327(Electronic))

25. Ren J, Ning Z, Asche CV, Zhuang M, Kirkness CS, Ye X, Fu J, Pan Q (2013) Trends and predictors in methadone maintenance treatment dropout in Shanghai, China: 2005-2011. Curr Med Res Opin 29(7):731-738

26. Peles E, Schreiber S, Adelson M (2010) 15-Year survival and retention of patients in a general hospital-affiliated methadone maintenance treatment (MMT) center in Israel. Drug Alcohol Depend 107(2-3):7

27. Villafranca SW, McKellar JD, Trafton JA, Humpfreys K (2006) Predictors of retention in methadone programs: a signal detection analysis. Drug Alcohol Depend 83:6

28. Brady TM, Salvucci S, Sverdlov LS, Male A, Kyeyune H, Sikali E, DeSale S, Yu P (2005) Methadone dosage and retention: an examination of the $60 \mathrm{mg} /$ day threshold. J Addict Dis 24(3):23-47

29. Faggiano F, Vigna-Taglianti F, Versino E, Lemma P (2003) Methadone maintenance at different dosages for opioid dependence. Cochrane Database Syst Rev 3:1-47

30. Reisinger HS, Schwartz RP, Mitchell SG, Peterson JA, Kelly SM, O'Grady KE et al (2009) Premature discharge from methadone treatment: patient perspectives. J Psychoactive Drugs 41(3):285-296

31. Deck D, Carlson M (2005) Retention in publicly funded methadone maintenance treatment in two Western States. J Behav Health Serv Res 32(1):17

32. Hser Y, Anglin M, Liu Y (1990-1991) A survival analysis of gender and ethnic differences in responsiveness to methadone maintenance treatment (MMT) center in Israel. Int $\mathrm{J}$ Addict 25(11a):20

33. Havens J, Latkin C, Pu M, Cornelius L, Bishai D, Huettner S et al (2009) Predictors of opiate agonist treatment retention among injection drug users referred from a needle exchange program. J Subst Abuse Treat 36(3):6

34. Gerra G, Di Petta G, D'Amore A, Iannotta P, Bardicchia F, Falorni $F$ et al (2007) Combination of olanzapine with opioidagonists in the treatment of heroin-addicted patients affected by comorbid schizophrenia spectrum disorders. Clin Neuropharmacol 30(3):8

35. Feinberg D, Hartman N (1991) Methadone and schizophrenia. Am J Psychiatry 148(12):2

36. Fareed A, Vayalapalli S, Stout S, Casarella J, Drexler K, Bailey S (2011) Effect of methadone maintenance treatment on heroin craving, a literature review. J Addict Dis 30(1):11

37. Carcoba L, Contreras A, Cepeda-Benito A, Meagher M (2011) Negative affect heightens opiate withdrawal-induced hyperalgesia in heroin dependent individuals. J Addict Dis 30(3):2

38. Grüsser S, Mörsen C, Wölfling K, Flor H (2007) The relationship of stress, coping, effect expectancies and craving. Eur Addict Res 13(1):7

39. Rang H, Dale M (2011) Rang and Dale's pharmacology, 7th edn. Saunders Elsevier, St. Louis 